\title{
0 Projeto de Lei 5595 e o discurso de ódio: a desconstrução da carreira docente no contexto pandêmico
}

\author{
The Bill 5595 and the hate speech: a deconstruction of \\ teaching career in the pandemic context
}

\author{
Júlio Araújo' \\ Marcos Randall Oliveira de Freitas ${ }^{2}$
}

\section{RESUMO}

A construção discursiva do ódio apresenta muitas facetas e, considerando isso, buscamos nos aproximar dos estudos sobre o fenômeno do discurso de ódio (GLUCKSMANN, 2007) na internet, focando na desconstrução da carreira docente no Twitter. Para a construção e análise dos dados, entrelaçamos a Análise do Discurso Crítica (FAIRCLOUGH, 2001) e a etnografia virtual (HINE, 2005) para investigarmos os processos sociodiscursivos engendrados no discurso de ódio aos professores a partir de comentários feitos no Twitter sobre o Projeto de Lei 5595 (BRASIL, 2020). Os resultados da pesquisa mostram-nos que o fortalecimento do discurso de ódio à carreira docente é um mecanismo de silenciamento dos docentes que estão empenhados na defesa dos direitos humanos. Dessa

1. Universidade Federal do Ceará - UFC. Fortaleza - Brasil. https://orcid.org/0000-00017399-3769. E-mail: araujo@ufc.br

2. Universidade Federal do Ceará - UFC. Fortaleza - Brasil. https://orcid.org/0000-00015980-0465. E-mail: randall.ufc@gmail.com 
forma, produzir, distribuir e consumir o discurso de ódio pelas redes sociais é uma prática discursiva nociva, pois demonstra uma intenção clara de destruir, de incitar o mal ou de promover o ódio a determinados grupos sociais minorizados.

Palavras-chave: Discurso de ódio; Carreira docente; PL 5595; Twitter.

\begin{abstract}
The discursive construction of hate presents many facets and, considering this, we sought to approach the studies on the phenomenon of hate speech (GLUCKSMANN, 2007) on the Internet, focusing on the deconstruction of the teaching career on Twitter. For data construction and analysis, we intertwined Critical Discourse Analysis (FAIRCLOUGH, 2001) and virtual ethnography (HINE, 2005) to investigate the sociodiscursive processes engendered in the discourse of hate towards teachers from comments made on Twitter about 5595 Bill (BRASIL, 2020). The results of the research show us that the strengthening of the discourse of hatred towards the teaching career is a mechanism of silencing teachers who are committed to the defense of human rights. Thus, producing, distributing and consuming hate speech through social networks is a harmful discursive practice, as it demonstrates a clear intention to destroy, to incite evil or to promote hatred towards certain minority social groups.
\end{abstract}

Keywords: Hate speech; Teaching career; Bill 5595; Twitter.

\title{
1. Introdução
}

O ódio está cada vez mais enraizado e escancarado nas relações cotidianas na web e na vida off-line. São construções discursivas que se multiplicam nas redes sociais, nos comentários das notícias e até em situações, aparentemente, banais do cotidiano. Nesse contexto, buscamos nos aproximar dos estudos sobre o fenômeno do discurso de ódio na internet, centralizando a atenção aos estudos sobre a desconstrução da carreira docente, visto que há muitos discursos de ódio à comunidade de professores e professoras nas redes sociais, em particular no Twitter, que mantém uma política contra a propagação do ódio em sua plataforma ${ }^{3}$. Essa tendência vem aumentando nos últimos anos em

3. https://help.twitter.com/pt/rules-and-policies/hateful-conduct-policy 
decorrência da democratização social e da influência do pensamento tradicional e conservador na política e, consequentemente, na sociedade. Para Fairclough (2001: 130):

Se a democratização do discurso e a personalização sintética podem ser ligadas à democratização substancial da sociedade, também estão ligadas de maneira controvertida aos processos de marquetização e especificamente a aparente mudança no poder dos produtores para os consumidores que é associada ao consumismo e as novas hegemonias a ele atribuídas.

Em função dessa mudança social, estudos como o desenvolvido por Ajakaiye et all (2019) mostra que as relações entre fake news e o discurso de ódio foi impactante durante o processo eleitoral das eleições presidenciais de 2015 na Nigéria. De acordo com esses autores, as fakes news forjaram e alimentaram o discurso de ódio a ponto de essa relação ter sido uma ferramenta que influenciou a decisão de voto do cidadão nigeriano. Após a análise dos dados, os autores recomendam que os líderes daquele país promulguem leis contra o discurso de ódio e fake news devido à sua natureza volátil de agravar a crise etno-religiosa na busca pela construção da nação da Nigéria

O mesmo aconteceu nos Estados Unidos, como evidencia as pesquisas feitas por Allcott e Gentzkow (2017) e Guess et al. (2018). Esses autores comprovam que, antes da eleição de 2016 ter favorecido à vitória de Donald Trump, muitas pessoas foram vítimas de fake news, tendo suas vidas, violentamente, expostas na internet. Outros pesquisadores argumentam que esse tipo de exposição gerou um impacto irrevocável nas referidas eleições, gerando crises e divisões severas na política americana (Spohr, 2017; Azzimonti; Fernandes, 2018).

Como podemos perceber, houve, nos últimos anos, um avanço no ideário conservador influenciado pela propagação de fake news e do discurso de ódio, engendrando vitórias de líderes de extrema direita, como Donald Trump, nos Estados Unidos, e de Jair Bolsonaro, no Brasil. No caso brasileiro, em 2018, ocorreu, também, não apenas a vitória de um presidente de extrema direita, mas também houve um aumento expressivo no número de deputados federais e senadores alinhados a esse pensamento, como membros das forças armadas e religiosos, 
carregando títulos de "bancada da bala" e "bancada da bíblia", além de defensores do movimento intitulado de Escola Sem Partido 4 .

As vitórias de Trump e Bolsonaro carregam em comum a ampla divulgação de fake news nas redes sociais, transmitidas por meio de perfis fakes, robôs virtuais e grupos de Whatssap, e a disseminação de discursos que ferem os direitos humanos, atacando grupos minoritários, como mulheres, travestis, quilombolas e indígenas. Com base nisso, os dados iniciais que apresentamos foram reunidos com o fito de construir o nosso objeto e de postular a fundamentação teórico-metodológica da nossa pesquisa. Segue, a seguir, um exemplo:

Figura 1 - Tweet sobre Bolsonaro e Abraham Weint

Em resposta a @AbrahamWeint
Bando de alienados...seguindo na a ideologia de
professores doutrinadores!! Sou professora da
rede pública a 14 anos e não suporto esse
sistema de ensino que nos foi empurrando goela
a baixo!! Torço bastante pelo sucesso da sua
gestão ministro e do presidente!!!
$\uparrow$

Fonte: Print coletado pelos pesquisadores (2021)

As construções discursivas presentes na imagem 1 levam-nos a refletir em relação à atual percepção sobre o trabalho docente, afinal, o professor, que antes era visto como herói, responsável pela construção do conhecimento, mediador do processo de ensino-aprendizagem, na atualidade, é visto, por um número cada vez maior de pessoas, como um sujeito doutrinador, que influencia negativamente e corrompe os alunos para um ideário esquerdista.

4. Segundo o site desse movimento, trata-se de uma iniciativa conjunta de estudantes e pais preocupados com o grau de contaminação político-ideológica das escolas brasileiras, em todos os níveis: do ensino básico ao superior. É uma associação informal, independente, sem fins lucrativos e sem qualquer espécie de vinculação política, ideológica ou partidária (Informação retirada do site http://www.escolasempartido.org/quem-somos, acesso em 15 de junho de 2021). 
A descrença no trabalho docente entrelaça-se com a desestabilização do discurso jornalístico e do pensamento científico. Essa tríade é acusada de carregar uma base ideológica que se aproxima do comunismo. Nesse contexto, ampliam-se as discussões sobre o projeto Escola Sem Partido, tão defendido por setores tradicionais e conservadores da sociedade.

Tanto a postagem do Twitter, apresentada na figura 1, quanto a existência de um coletivo como o "Escola Sem Partido" nos remontam às ideias discutidas por Freire (1993) segundo para quem não existe conhecimento neutro. Sendo assim, a construção do conhecimento perpassa por uma lógica ideológica, o que oportuniza professores e alunos a debaterem sobre diversos assuntos com o fito de ampliar a argumentação e o olhar sobre temáticas variadas, como política, sexualidades, inclusão social, direitos humanos etc.

Nesse contexto, esta pesquisa tem como ponto de partida as discussões sobre o Projeto de Lei 5595 (BRASIL, 2020), que reconhece a Educação Básica e a Educação Superior, em formato presencial, como serviços e atividades essenciais e estabelece diretrizes para o retorno seguro às aulas presenciais em pleno contexto da pandemia de COVID-19. O objetivo é investigar, sob o viés da Análise do Discurso Crítica, os processos sociodiscursivos engendrados na desconstrução da carreira docente durante a crise sanitária supracitada a partir dos comentários sobre o supracitado PL.

Assim, para dar corpo ao nosso objetivo, além desta introdução na qual construímos o nosso objeto de estudo, a distribuição das informações no presente texto ainda conta com três seções: 1) o debate sobre as redes de ódio e a desconstrução da carreira docente; 2) a construção do arcabouço teórico-metodológico; e 3) o mapeamento do discurso de ódio contra os professores. Em seguida, para finalizar, traçamos algumas considerações sobre os discursos construídos a partir do debate desse PL.

\section{O ódio pelo ódio: a desconstrução da carreira docente}

A construção discursiva do ódio apresenta muitas facetas e tem relação direta com os contextos social, cultural, político e econômico, 
afinal, há uma luta ideológica e hegemônica para massacrar e destruir diferentes grupos minoritários. Para Glucksmann (2007: 11), “[...] o ódio existe, todos nós já nos deparamos com ele, tanto na escala microscópica dos indivíduos como no cerne de coletividades gigantescas".

Nessa perspectiva, a educação e a ciência são, constantemente, colocadas à prova, pois são mecanismos de transformação social, ou seja, para os odiosos, o combate à educação e à ciência torna-se um fio condutor de desgaste e perseguição. Para Arendt (2008: 153), "a força e o perigo dos preconceitos se explicam, entre outros, pelo fato de terem sempre oculto dentro de si algo do passado". Ao analisarmos as mudanças históricas dos profissionais da educação, percebemos o quão esse processo foi marcado por lutas e resistências. Por isso, esse passado combativo é visto hoje como uma ameaça aos ideais tradicionais e conservadores. Nesta pesquisa, escolhemos trabalhar especificamente com os professores - através da carreira docente - já que é esse grupo que está na "linha de frente" dos espaços escolares, e que tem sido alvo de discursos de ódio por parte do atual governo e seus apoiadores, principalmente na pandemia, pelo fato de resistirem a retornar para as escolas sem terem sido imunizados.

No Brasil, de forma histórica, a carreira docente vem sofrendo sucessivas perseguições e constante desvalorização, prova maior é o reduzido valor do piso salarial dos profissionais do magistério, que está bem distante de se equiparar aos demais profissionais do ensino superior. Ademais, há profundas perseguições odiosas em relação às vozes dos/das docentes sobre temáticas sociais. Para Santos e Silva (2013: 3),

o ódio é uma questão factual e sua intensidade como movimento transformador na sociedade dependerá de como ele é divulgado. O discurso do ódio é uma forma especial de propagação do mal e o meio informacional tem papel fundamental no atual contexto histórico.

Para esses inquisidores, professoras e professores devem se isentar de assuntos considerados polêmicos e devem focar na ideia fixa e tradicional de transmissão dos conteúdos escolares, mantendo-se neutros em relação ao que acontece fora dos espaços escolares, reforçando a ideia de uma educação para a alienação. Contudo, segundo Freire 
(2000c: 37), “[...] não pode existir uma prática educativa neutra, descomprometida, apolítica. A diretividade da prática educativa que a faz transbordar sempre de si mesma e perseguir um certo fim, um sonho, uma utopia, não permite sua neutralidade".

Esse distanciamento da neutralidade implica aos odiosos uma construção empenhada e hegemônica com o fito de criar semelhanças entre a liberdade de expressão e o discurso de ódio. Ao transformar esses "dois lados em uma mesma moeda", esses grupos colocam-se como pessoas que podem dizer (e até odiar) em prol da desconfigurada liberdade de expressão.

Torna-se vital a compreensão de que o processo de ensino-aprendizagem se aproxima da construção crítica e coletiva do debate sobre múltiplas temáticas para além dos conteúdos dos livros didáticos. Por isso, as diferentes vozes e o respeito à dignidade humana são premissas fundamentais para o fortalecimento de uma sociedade mais igualitária e digna. Para Hooks (2013: 22), “a voz engajada não pode ser fixa e absoluta. Deve estar sempre mudando, sempre em diálogo com um mundo fora dela".

Esse constante diálogo possibilita que docentes, alunos e, consequentemente, toda a comunidade escolar estejamos imersos no contexto social, permitindo que o debate sobre o papel social da educação permaneça entrelaçado com o papel político do processo educacional, inclusive numa perspectiva de combate à proliferação de fake news. Segundo Souza e Padrão (2017: 38):

Há um diálogo claro entre a ascensão das fake news e a pós-verdade, eleita palavra do ano pelo dicionário Oxford em 2016. Ou seja, aquilo em que as pessoas escolhem acreditar importa mais do que a verdade dos fatos. Dessa forma, ao encontrar uma notícia que se adeque às suas convicções pessoais, as pessoas não hesitam em compartilhá-la sem ao menos verificar a procedência dos fatos.

O acesso mais rápido aos diferentes tipos de informações atrelado à subjetividade das convicções pessoais aumenta as nuances de ódio aos grupos minoritários - aqui representados pelos professores. Nessa conjuntura, os atores sociais hegemônicos tentam, por meio de diferentes estratégias ideológicas, como, por exemplo, a disseminação de fake 
news, permanecerem no status quo das relações de poder, ampliando as desigualdades sociais.

Aos nos questionarmos sobre as posições sociais dos sujeitos, colocamo-nos contrários à naturalização das coisas, das atitudes e das ações, além de desestabilizarmos as condições hegemônicas impostas pelas diferentes instituições sociais e pela classe dominante. Por isso, é crucial que os educadores enxerguem o ato político da educação, propiciando a emancipação das pessoas e a construção coletiva da dignidade humana.

\section{Nas trilhas da pesquisa: construindo o arcabouço teórico-metodológico}

Fairclough (2001) mostra-nos que existem três aspectos do efeito construtivo do discurso: 1) contribui para a construção das identidades sociais; 2) auxilia no desenvolvimento das relações sociais entre as pessoas; e 3) coopera para a concepção de sistemas de conhecimentos e crenças. Por isso, aproximamo-nos da proposta teórico-metodológica da Análise do discurso Crítica (ADC), por meio da etnografia virtual, haja vista a observação e a análise crítica dos pesquisadores sob o objeto aqui analisado.

Nesse contexto, para a construção e análise dos dados, entrelaçamos a ADC e a etnografia virtual para investigarmos os processos sociodiscursivos engendrados na desconstrução da carreira docente a partir dos comentários postados no Twitter sobre o supracitado Projeto de Lei. Nosso objetivo é entrelaçar os discursos coletados no tweets, para que as pistas contidas nos comentários possam ser interpretadas, ou seja, vista "[...] com outros olhos, com olhos de um estrangeiro em busca de significados" (TRAVANCAS, 2009: 100). Na construção do arcabouço teórico-metodológico, utilizamos as três dimensões propostas por Fairclough (2001): texto, prática discursiva e prática social, voltando nosso olhar para os elementos: vocabulário, coesão, produção, hegemonia e ideologia.

Para tanto, a etnografia virtual, como um método adaptável, possibilitou-nos múltiplos percursos no processo de recolha dos tweets, 
como as práticas de observação, a contextualização e interpretação sistemática dos dados (FRAGOSO; RECUERO; AMARAL, 2012).

Os dados de nossa pesquisa foram coletados na rede social Twitter no período de 10 de junho de 2021 a 15 de junho 2021, portanto, ainda no contexto da pandemia de COVID-19. Durante esse período, foram coletadas 10 postagens, porém, decidimos fazer a análise de três postagens, seguindo os seguintes critérios: quantidade de retweets $\mathrm{e}$ aproximação com a temática do nosso estudo. No momento em que escrevemos esse artigo bem menos de $50 \%$ da população brasileira recebeu a primeira dose da vacina ${ }^{5}$.

Para realização da geração do corpus no Twitter, utilizamos uma postagem (figura 2) da deputada federal Carla Zambelli, com um pouco mais de 1,2 milhões de seguidores. A quantidade de retweets, de comentários e de curtidas ratificam o forte engajamento do perfil da supracitada parlamentar no Twitter.

Figura 2 - Tweet da deputada Federal Carla Zambelli

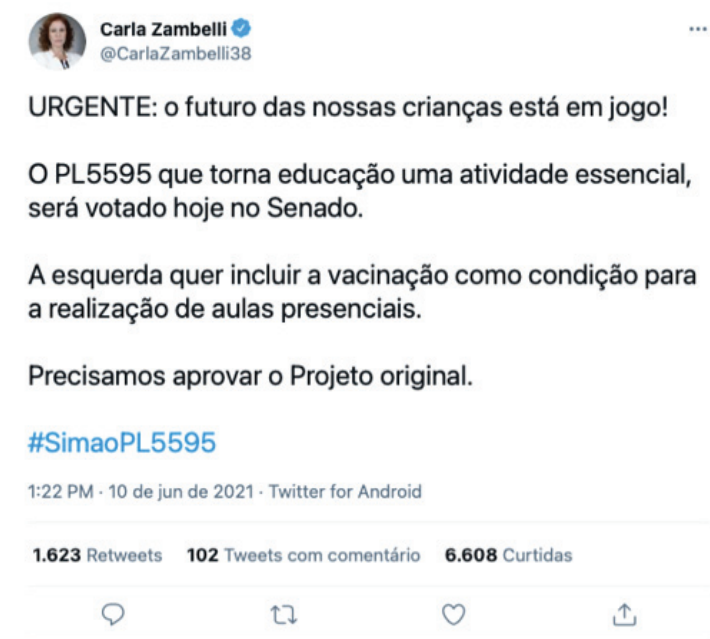

Fonte: Print coletado pelos pesquisadores (2021)

5. Segundo o mapa de vacinação contra covid-19 no Brasil, apenas $34,74 \%$ da população brasileira recebeu a primeira dose. Fonte: $<$ https://especiais.gl.globo.com/bemestar/vacina/2021/ mapa-brasil-vacina-covid/> Acesso em 1 jun. 2021. 
Os tweets foram recolhidos pelo recurso print, diretamente dos perfis dos dois pesquisadores do presente artigo, pois ambos mantemos uma conta da referida rede social. Na etnografia virtual, a escolha pela permanência ou não do silêncio dos pesquisadores precisa ser refletida (HINE, 2005), já que influencia no arcabouço teórico-metodológico da pesquisa. Ao refletirmos sobre a desconstrução da carreira docente a partir do discurso de ódio, escolhemos obter os dados de forma silenciosa, atuando como pesquisadores-observadores, com o fito de perceber as estratégias discursivas construídas pelas pessoas nos tweets escolhidos, sem interferirmos de forma direta nos comentários postados.

Escolhemos a rede social Twitter devido ao grande número de usuários cadastrados nessa rede, ultrapassando a marca dos 500 milhões ${ }^{6}$ de perfis, o que gera uma enorme potencial de debate e argumentação permitido em até 280 caracteres, ampliando as possibilidades do ciberativismo. Além disso, como já assinalado, essa rede mantém uma política de combate ao discurso de ódio, conforme podemos observar no site dessa rede social ${ }^{7}$.

Considerando isso, o desvelamento das estratégias discursivas engendradas no processo de desconstrução da carreira docente levou-nos a analisar o percurso do ódio através de uma postagem feita pela deputada federal Carla Zambelli. Em virtude dos princípios éticos da pesquisa e da preservação de face dos autores dos comentários a referida postagem, decidimos por chamá-los de P1, P2, etc. A letra ' $\mathrm{P}$ ' faz referência à ideia de participante e o número é relativo à sequência dos comentários postados pelos participantes.

Como já anunciado, esta pesquisa está alicerçada na Análise do Discurso Crítica, a qual (re)constrói modelos teórico-metodológicos a partir do entrelaçamento entre as práticas de linguagem e as práticas

6. Essa informação foi retirada do site: (Informação retirada do site http://ecmetrics.com/ pt/o-brasil-e-o-segundo-colocado-em-numero-de-usuarios-do-twitter/, acesso em 12 de junho de 2021).

7. Segundo as palavras publicadas no site do Twitter: "temos o compromisso de combater o assédio motivado por ódio, preconceito ou intolerância, particularmente aquele que tem o objetivo de silenciar as vozes de quem é historicamente marginalizado. Por esse motivo, proibimos comportamentos de assédio direcionados a indivíduos relacionados a categorias protegidas." $<$ https://help.twitter.com/pt/rules-and-policies/hateful-conduct-policy> 
sociais, possibilitando o desvelamento das opressões nas múltiplas esferas sociais. Para isso, utilizamos o modelo tridimensional proposto e aprimorado por Fairclough (1992), no qual distingue três dimensões no discurso: texto, prática discursiva e prática social.

De acordo com Fairclough (1992), a dimensão textual envolve os aspectos formais do texto, atrelando as formas linguísticas às noções de significado. Esse processo envolve o vocabulário, a gramática das palavras e a coesão. A prática discursiva analisa os contextos de produção, de distribuição e de consumo, além das relações presentes nos atos de fala, na coerência e na intertextualidade. Na prática social, há o entrelaçamento das práticas de ideologia e hegemonia, o que implica no poder e suas relações. As categorias de análise aqui utilizadas, portanto, entrelaçam-se na tríade: texto - vocabulário e estrutura textual; prática discursiva - produção; e a prática social - hegemonia e ideologia.

\section{De olho no corpus: mapeando o discurso de ódio contra os professores}

A trajetória durante a construção e, sobretudo, durante o exercício analítico dos dados permitem-nos perceber as artimanhas discursivo-ideológicas engendradas pelos usuários durante a interação que eles fazem entre si para discutir a postagem feita pela deputada já referida. Além dos comentários, sinalizamos o compartilhamento e as curtidas das postagens, pois essas ações não são inocentes, já que expandem o raio de alcance do discurso de ódio contra a profissão docente.

Na figura 3, a seguir, P1 utiliza-se da $1^{\text {a }}$ pessoa do plural para ratificar a ideia de que ele e outras pessoas estavam esperando pela aprovação do PL e, consequentemente, o retorno imediato dos professores ao ensino presencial, pois, segundo $\mathrm{P} 1$, há muito "professor folgado". 
Figura 3 - Tweet do P1

\section{Em resposta a @CarlaZambelli38}

Estamos anciosos para isto porque o que tem de professor folgado não querendo o retorno as aulas fica até feio para se dizerem educadores. Até isto a esquerda fez deixou muitos preguisosos e a ideia de vida fácil.

○ 10

$\uparrow 1$

○ 7

Fonte: Print coletado pelos pesquisadores (2021)

P1 utiliza-se dos vocábulos 'professor' e 'educador' para diferenciar esses dois papeis. Essa ideia desassocia e traz a carga semântica de que os que não querem o retorno das aulas presenciais sem a vacina contra a COVID-19 não são educadores. Em uma tentativa de avançar em sua argumentação, P1 traz à tona a ideia de que a esquerda oferece 'vida fácil' e torna as pessoas 'preguiçosas'.

Como podemos observar, as escolhas linguísticas que materializam essa postagem sinalizam para o discurso de ódio ao professor uma vez que expressões como "professor folgado", "preguiçosos" e "vida fácil" sinalizam como marcas de um argumento que se constrói em função de desvalorizar e deslegitimar o trabalho dos docentes durante a pandemia, investindo na ideia de que o professor não trabalha e, por isso, está distante da função social da profissão. Esse recurso serve de base para a construção e propagação de fake news e fortalecimento do caráter hegemônico contrário à valorização docente.

Para Fairclough (2001: 122), "hegemonia é um foco de constante luta sobre pontos de maior instabilidade entre classes e blocos para construir, manter ou romper alianças e relações de dominação/subordinação, que assumem formas econômicas, políticas e ideológicas". Na figura 3, ao mostrar que a 'esquerda deixou muitos preguiçosos', P1 tenta fortalecer o rompimento entre direita e esquerda, deixando subentendido que o bloco da direita não é preguiçoso e, consequentemente, é responsável pelo desenvolvimento econômico do país.

O tweet de P1 apresenta 10 respostas e 7 curtidas, ou seja, a voz de P1 estabelece uma polifonia de ódio, na medida em que, pelo menos mais 7 pessoas concordam com as representações de professor folgado e preguiçoso defendidas pelo autor da supracitada postagem. Esses 
números representam o engajamento da postagem e as aproximações ideológicas dos envolvidos no evento comunicativo, como podemos perceber na figura 4, a seguir.

Figura 4 - Tweet do P2

\section{Em resposta a @CarlaZambelli38}

No escolas públicas que acontece isso, PQP as particulares e militares estão funcionando, querem acabar c nossas crianças.

Q 1 七】 $1 \quad 07$

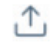

Fonte: Print coletado pelos pesquisadores (2021)

A postagem acima mostra que, $\mathrm{P} 2$, além de carregar uma visão preconceituosa sobre as escolas públicas regulares, diferenciando a realidade das escolas públicas regulares das particulares e militares, usa esse recurso ideológico de fragmentar as instituições com o objetivo de desestabilizar os espaços públicos, promovendo a ideia de que o que é público não presta ou não funciona, ampliando as diferenças sociais diante dessas instituições. Além disso, há o fortalecimento do discurso engendrado sobre um "possível" benefício em prol do retorno dos militares. Para Fairclough (2001), a prática ideológica transforma o significado de mundo e as relações de poder, por isso, o discurso militarista reforça a ideia de caos e desorganização para hierarquizar as relações de poder e rememorar os tempos sombrios do Golpe Militar de $1964^{8}$.

Ademais, P2 traz a sigla PQP, que abrevia uma expressão de baixo calão, reforçando o ódio aos docentes. De acordo com Gitari et al (2015: 215, tradução nossa),

a disseminação de mensagens de ódio pode ser feita por meio de sites dedicados associados a um grupo coeso de membros, mas também pode ser por meio de sites populares como o Yahoo!, Twitter ou Facebook, onde questões atuais ou artigos de notícias podem gerar respostas com linguagem estereotipada.

8. No dia 31 de março de 1964, um golpe militar foi deflagrado contra o governo legalmente constituído de João Goulart. (Informação retirada do site https://cpdoc.fgv.br/producao/ dossies/FatosImagens/Golpe1964, acesso em 4 de julho de 2021). 
O comentário ainda apresenta o uso do pronome possessivo 'nossas' relacionado ao sintagma nominal 'crianças' para legitimar o traço ideológico contrário à carreira docente. Desse modo, a afirmação segundo a qual os professores "querem acabar c nossas crianças" se alinha ao propósito de desconstruir a imagem profissional do professor, pois esse tipo de escrita não apenas deprecia a profissão docente, mas também pode suscitar danos e perigos à pessoa que assume essa profissão.

Ao relacionarem o programa Escola Sem Partido ao trabalho dos professores, Moura e Salles (2018: 137) afirmam que o "discurso de ódio contra os professores se fundamenta principalmente na falácia de que estes estariam transformando seus alunos em gays e lésbicas". Uma das pautas desse Programa é mostrar que os docentes se utilizam da "ideologia de gênero" para "transformar" a orientação sexual das crianças. Dois pontos precisam ficar bem claros nessa discussão: 1) não existe ideologia de gênero, mas sim discussões sobre o alinhamento dos currículos com noções sobre sexualidade e direitos reprodutivos, por exemplo; e 2) ninguém transforma a orientação sexual de ninguém, pois a orientação é construída a partir das experiências pessoais e coletivas de cada indivíduo.

Outro comentário que segue o mesmo padrão é o que mostramos na sequência.

Figura 5 - Tweet do P3

\section{Em resposta a @CarlaZambelli38}

A MAIORIA destes professores são PTralhas, é contra o TRABALHO, mas querem receber seus salários final do mês.

Enquanto nossas crianças presa em casa sem aprender direito, nem todos tem condições de ter aulas on-line. Enfim..

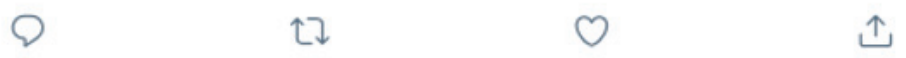

Fonte: Print coletado pelos pesquisadores (2021)

Na figura 5, P3 inicia seu tweet a partir da expressão 'a maioria' em letras maiúsculas para deixar claro que a maior parte dos docentes 
no Brasil está contaminada por uma ideologia de esquerda, o que representa uma ameaça às crianças. A crítica à educação se mescla com a condenação ao Partido dos Trabalhadores e essa postura nos remete ao movimento Escola sem Partido cuja missão seria combater a suposta doutrinação que os professores estariam impondo às crianças (Moura; Salles, 2018).

Esse comentário se alinha ao discurso de ódio na medida em que é motivado por preconceitos à educação como uma parte da sociedade que se deixou corromper pela esquerda petista. $\mathrm{O}$ uso da expressão "PTralhas" mostra a carência de uma argumentação racional, fundada apenas nas representações construídas de que nem todos os professores são petistas, segundo P3. A autora dessa postagem se utiliza das letras maiúsculas para enfatizar a ideia de que existe uma grande quantidade de professores envolvidos com o 'petismo', o que descredenciaria esses profissionais de um trabalho sério. Além disso, usa também o vocábulo 'trabalho' em letras maiúsculas, aproximando a ideia de oposição entre trabalho e professores, isto é, docentes não trabalham. Seguindo a sua linha argumentativa, P3 faz uso da conjunção adversativa 'mas' para ressaltar a ideia de que mesmo sem trabalhar, os professores querem receber seus salários.

Por fim, ao usar a expressão 'nossas crianças', P3 se arvora de juiz quando investe na construção de um tom apelativo para enfatizar que as crianças estão 'presas em casa', com o fito de persuadir os interlocutores em favor da ideia defendida no tweet. Para isso, a expressão 'nossas crianças' se revela como uma estratégia argumentativa apelativas a fim de investir discursivamente na busca por uma aproximação e afetividade com seus leitores.

\section{Conclusão}

O fortalecimento do discurso de ódio à carreira docente é um mecanismo de silenciamento das múltiplas vozes de docentes que estão empenhados na desconstrução das ideologias dominantes e na defesa dos direitos humanos.

Nesse contexto, a possível aprovação do PL 5595, reconhecendo a Educação Básica e a Educação Superior, em formato presencial, 
como serviço essencial traz grandes prejuízos à comunidade escolar, principalmente devido à alta taxa de transmissão do Coronavírus em nosso país. Além disso, os discursos construídos a partir do debate desse PL nos fazem tecer algumas considerações:

- O conhecimento e a ciência são desconstruídos com o fito de ampliar a disseminação de fake news e do discurso de ódio;

- A desconstrução da carreira docente é intencional e alicerçada na ideia de que os docentes são inimigos do ideário conservador;

- O uso do vocábulo 'essencial' no texto do PL 5595 refere-se a presencialidade da rotina escolar, porém não ressalta a essencialidade dos investimentos na área educacional;

- A diferenciação semântica dos vocábulos 'professor' e 'educador' é uma estratégia discursiva-ideológica para destruir a imagem desses profissionais;

- Durante a pandemia, mesmo trabalhando de forma sobrecarregada, a imagem construída dos docentes enquadra-se na ideia de que esses profissionais 'não querem trabalhar' porque são preguiçosos.

Sob a ótica desse debate, o viés discursivo engendrado a partir das práticas hegemônicas e ideológicas dos grupos conservadores perpassa pela forte e constante desconstrução da carreira docente. Essa prática questiona o trabalho realizado pelos profissionais da Educação e deslegitima a autonomia docente, ecoando a desvalorização dos educadores e a perseguição ao livre pensar docente (Penna, 2015).

Produzir, distribuir e consumir o discurso de ódio é uma prática discursiva danosa, pois demonstra uma intenção clara de destruir, de incitar o mal ou de promover o ódio a determinados grupos sociais minorizados. O ambiente da mídia social e da Web 2.0 interativa fornece um terreno particularmente fértil para a criação, compartilhamento e troca de mensagens de ódio contra um grupo inimigo percebido pelos odiadores. Eles vomitam suas verborragias nos sites de revisão de notícias, nos fóruns da Internet, nos grupos de discussão, bem como em sites de redes sociais. Em função disso, é tarefa de todos, em especial, 
da escola, promover atividades que ampliem os letramentos digitais críticos a fim de combater essa prática social.

Finalmente, é importante destacar que reconhecemos que o nosso estudo não apresenta dados empíricos sobre como o discurso de ódio estimula os crimes de ódio ou preconceito na vida real dos professores brasileiros. Em função disso, consideramos relevante que outras pesquisas sejam realizadas de modo a ouvirmos relatos específicos sobre os danos e as consequências que o discurso de ódio tem gerado na vida dos docentes do país durante esse período da pandemia de COVID-19.

\section{Agradecimentos}

O presente trabalho foi realizado com apoio da Coordenação de Aperfeiçoamento de Pessoal de Nível Superior - Brasil (CAPES) Código de Financiamento 001, processo 88887.369629/2019-00.

\section{Conflito de interesses}

$O(A)$ autor(a) declara não ter qualquer conflito de interesse, em potencial, neste estudo e assume responsabilidade total pelo conteúdo do artigo.

\section{Contribuição dos autores}

Nós, Júlio Araújo e Marcos Randall Oliveira de Freitas, declaramos, para os devidos fins, que não temos qualquer conflito de interesse, em potencial, neste estudo. Todos nós participamos da conceptualização do estudo, construímos o arcabouço teórico-metodológico, desenho do estudo, análise formal dos dados, análise qualitativa dos dados, administração do projeto, supervisão do projeto, coleta dos dados, geração dos dados, validação e edição dos dados. Todos os autores aprovam a versão final do manuscrito e são responsáveis por todos os aspectos, incluindo a garantia de sua veracidade e integridade.

\section{Referências}

Ajakaiye, Olanrewaju O. P. et al (2019). Hate Speech and Fake News: a study of meanings and perceptions in Nigerian Political Culture. International Journal of Scientific and Engineering Research 10(5):15, p. 1670- 1684. https://doi.org/10.14299/ijser.2019.05.07 
Allcott, H., \& Gentzkow, M. (2017). Social media and fake News in the 2016 election. Journal of Economic Perspectives, 31(2), 211-236. https://doi.org/10.1257/jep.31.2.211

Arendt, Hannah (2008). A promessa da política. Tradução: Pedro Jorgensen Jr. Rio de Janeiro: DIFEL.

Azzimonti, M., Fernandes, M. (2018). Social media networks, fake news, and polarization. NBER Working Paper No. 24462. https:// doi.org/10.3386/w24462

Brasil (2020). Câmara dos Deputados. Projeto de Lei no 5595, de 17 de junho de 2020. Reconhece a educação básica e a educação superior, em formato presencial, como serviços e atividades essenciais e estabelece diretrizes para o retorno seguro às aulas presenciais. Brasília: Câmara dos Deputados. https://www25.senado.leg.br/web/ atividade/materias/-/materia/148171. (accessed August 7, 2021).

Fairclough, N. (2001). Discurso e Mudança Social. Brasília: Universidade de Brasília.

Fragoso, S., Recuero, R., \& Amaral, A (2011). Métodos de Pesquisa para Internet. Porto Alegre: Sulina.

Freire, P. (2000). Pedagogia da indignação: cartas pedagógicas e outros escritos. São Paulo: UNESP.

. (1993). Política e Educação: ensaios. 5. ed. São Paulo: Editora Cortez. (Col. Questões de nossa época).

Gitari, N. D., Zuping, Z., Damien, H., \& Long, J. (2015). A lexiconbased approach for hate speech detection. International Journal of Multimedia and Ubiquitous Engineering, 10(4), 215-230. https://doi. org/10.14257/ijmue.2015.10.4.21

Glucksmann, A. (2007). O Discurso do Ódio. Rio de Janeiro: Difel.

Guess, A., Nyhan, et al. (2018). Selective exposure to misinformation: evidence from the con- sumption of fake news during the 2016 US presidential campaign. Working Paper. European Research Council. https://about.fb.com/wp-content/uploads/2018/01/fake-news-2016. pdf. (accessed August 10, 2021).

Hine, Christine (2004). Etnografía virtual. Nuevas Tecnologías y Sociedad. Barcelona: Editorial UOC.

Hooks, B. (2013). Ensinando a transgredir: a educação como prática da liberdade. São Paulo Martins Fontes.

Moura, F., Salles, D. (2018). Escola Sem Partido e o ódio aos professores que formam crianças (des)viadas. Revista Periódicus, Passo Fundo, v. 1, n. 9, p. 136-160, maio./out.

Penna, F. (2015). O ódio aos professores. Movimento Liberdade para Educar. Rio de Janeiro. https://liberdadeparaensinar.wordpress. com/2015/09/18/o-odio-aos-professores. (accessed August 12, 2021). 
Santos, M. A. M., Silva, Mônica T. M. (2015). Discurso do Ódio na Sociedade da Informação Preconceito, Discriminação e Racismo em Redes Sociais. In: XXII Congresso Nacional do CONPEDI/ UNINOVE - São Paulo-SP, 2013, São Paulo. Sociedade global e seus impactos sobre o estudo e a efetividade do Direito na contemporaneidade. Florianópolis: FUNJAB, 82-99.

Souza, C. A., Padrão, V. (2017). Quem lêtanta notícia (falsa)? Entendendo o combate contra as "fakes news". ITs Rio. Rio de Janeiro. https:// feed.itsrio.org/quem-lê-tanta-not\%C3\%ADcia-falsa-entendendo-ocombate-contra-as-fake-news-70fa0db05aa5. (accessed August 2, 2021).

Spohr, D. (2017). Fake news and ideological polarization: filter bubbles and selective exposure on social media. Business Information Review 34 (3): 150-160. https://doi.org/10.1177/0266382117722446

Travancas, I. (2009). Fazendo etnografia no mundo da comunicação. In: Duarte, J., \& Barros, A. (Ed.). Métodos e técnicas de pesquisa em comunicação. São Paulo: Editora Atlas.

Recebido em: 06/09/2021 Aprovado em: 03/10/2021 